\title{
Practical Interests, Relevant Alternatives, and Knowledge Attributions: an Empirical Study
}

\author{
Joshua May • Walter Sinnott-Armstrong • \\ Jay G. Hull • Aaron Zimmerman
}

Published online: 12 January 2010

C The Author(s) 2009. This article is published with open access at Springerlink.com

\begin{abstract}
In defending his interest-relative account of knowledge, Jason Stanley relies heavily on intuitions about several bank cases. We experimentally test the empirical claims that Stanley seems to make concerning our common-sense intuitions about these cases. Additionally, we test the empirical claims that Jonathan Schaffer seems to make, regarding the salience of an alternative, in his critique of Stanley. Our data indicate that neither raising the possibility of error nor raising stakes moves most people from attributing knowledge to denying it. However, the raising of stakes (but not alternatives) does affect the level of confidence people have in their attributions of knowledge. We argue that our data impugn what both Stanley and Schaffer claim our common-sense judgments about such cases are.
\end{abstract}

J. May $(\bowtie) \cdot$ A. Zimmerman

Department of Philosophy, University of California, Santa Barbara, 5631 South Hall, Santa Barbara, CA 93106-3090, USA

e-mail: jdmay@umail.ucsb.edu
A. Zimmerman
e-mail: azimmerman@philosophy.ucsb.edu

W. Sinnott-Armstrong

Department of Philosophy, Dartmouth College, 6035 Thornton Hall, Hanover, NH 03755-3692, USA e-mail: wsa@dartmouth.edu

J. G. Hull

Department of Psychological and Brain Sciences, Dartmouth College,

6207 Moore Hall, Hanover, NH 03755-3692, USA

e-mail: jay.hull@dartmouth.edu 


\section{Introduction}

In Knowledge and Practical Interests (2005), ${ }^{1}$ Jason Stanley argues carefully and forcefully for an important and surprising thesis: whether someone knows something depends, in part, on facts about the personal costs of her being wrong in believing it. Stanley calls his view "interest-relative invariantism" and situates it within a larger pragmatist or anti-intellectualist trend in recent epistemology that includes the work of John Hawthorne (2004) as well as Jeremy Fantl and Matthew McGrath (2002).

Stanley's main argument for the interest-relativity of knowledge rests on a series of examples that he introduces early and cites often. For simplicity, we will focus on two of his cases:

Low Stakes. Hannah and her wife Sarah are driving home on a Friday afternoon. They plan to stop at the bank on the way home to deposit their paychecks. It is not important that they do so, as they have no impending bills. But as they drive past the bank, they notice that the lines inside are very long, as they often are on Friday afternoons. Realizing that it isn't very important that their paychecks are deposited right away, Hannah says, "I know the bank will be open tomorrow, since I was there just 2 weeks ago on Saturday morning. So we can deposit our paychecks tomorrow morning”. (pp. 3-4)

High Stakes. Hannah and her wife Sarah are driving home on a Friday afternoon. They plan to stop at the bank on the way home to deposit their paychecks. Since they have an impending bill coming due, and very little in their account, it is very important that they deposit their paychecks by Saturday. Hannah notes that she was at the bank 2 weeks before on Saturday morning, and it was open. But, as Sarah points out, banks do change their hours. Hannah says, "I guess you're right. I don't know that the bank will be open tomorrow". (p. 4)

Though it is not explicitly stated in the cases themselves, Stanley asks readers to assume that the bank will be open on Saturday (p. 5). Stanley also suggests that in each scenario Hannah should be thought of as having "the same non-practical basis for the belief that the bank will be open the next morning" (p. 6). The only relevant difference between the two cases is supposed to be the importance to the protagonist of the bank being open. Since, Stanley claims, "our" intuitive verdicts are that Hannah knows that the bank will be open in Low Stakes but does not know this in High Stakes, the examples "provide a prima facie case for the thesis that knowledge is not just a matter of non-practical facts, but is also a matter of how much is at stake" (p. 6, his emphasis) as well as "powerful intuitive evidence for an antecedently plausible principle concerning the relation between knowledge and action" (p. 11).

Although Stanley's main argument rests squarely on intuitions about his bank cases, he disavows any claim that these intuitions are "indefeasible" or that they play a role "akin to the role of observational data in scientific theory" (p. 12). Nonetheless, Stanley often writes in the first-person plural about "our" reactions,

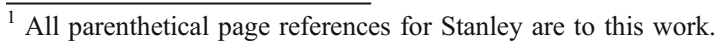


and the intuitions "we" have, as if all or almost all of us agree with him about the cases as described. He confidently cites these intuitions to argue for claims about other examples (p. 7) and to argue against alternative views of knowledge (p. 8). Furthermore, he denies that "our" intuitions can be explained away as "framing effects" (p. 9) or "random noise" (p. 11); and he goes on to admit that he never "seriously consider[s] rejecting these intuitions" and that his "central interest is to evaluate accounts that make as much sense of these intuitions as possible" (p. 13; cf. p. v).

In his critique of Stanley, Jonathan Schaffer (2006) points out several flaws in Stanley's versions of the bank cases. Given the cases as described by Stanley, Schaffer accepts that "most people intuit that Hannah knows in Low [Stakes], but does not know in High [Stakes]", but Schaffer points out that "Low [Stakes] and High [Stakes] differ... not only over what is at stake for the subject but also over whether the possibility of error is explicitly mentioned (which happens only in High [Stakes])" (p. 88). ${ }^{2}$ A relevant alternative possibility is made salient in High Stakes when Sarah points out that "banks do change their hours", something she does not do in Low Stakes. In addition, Schaffer points out that bias may be introduced because "Low [Stakes], and High [Stakes], explicitly include [Stanley's] preferred verdicts" (p. 88) since what the protagonist says (i.e. "I know..." in Low Stakes and "I guess I don't know..." in High Stakes) is exactly what Stanley claims is true of both cases. Moreover, though Schaffer doesn't mention it, we submit that in explicitly saying "I guess I don't know that the bank will be open” in High Stakes, Hannah conveys to the reader that she lacks the kind of conviction many think necessary for knowledge. Unless Hannah is described as being just as certain that the bank will be open on Saturday in High Stakes as she is in Low Stakes, the examples cannot be used to isolate the role that decidedly practical interests play in our attributions of knowledge.

After constructing improved alternative versions of Stanley's scenarios, Schaffer hazards his own interest-invariant hypothesis about our reactions: "When the possibility of error is not made salient..., I tend to intuit that the subject knows; but when the possibility of error is made salient..., I tend to intuit that the subject does not know. The stakes play no role" (p. 90).

It is surprising that neither Stanley nor Schaffer cites any evidence that their intuitions are shared by anyone else. Sometimes Schaffer is careful to say only "I tend to intuit", but he soon switches back to "our intuitions" (p. 89). And Stanley continually writes about the "intuitions we have" about such cases (e.g. pp. 9-12, $33,98,115,123,179)$. Their claims, then, are not limited to bits of autobiography, but are supposed to be taken as generalizations about the views of common folk. Of course, they must have this broader scope if they are to shed light on our shared conceptual framework as distinguished from a single person's idiosyncratic way of thinking about knowledge and related phenomena.

What follows is a report of our attempts to experimentally test Stanley's and Schaffer's claims about our common-sense intuitions about such cases. The results of these experiments are mixed, and in a particularly interesting way. Stanley's claim that most ordinary people would attribute knowledge to Hannah in Low Stakes but not High Stakes is impugned by the data, as a majority of subjects attributed

${ }^{2}$ All parenthetical page references for Schaffer are to his (2006). 
knowledge in both cases. In addition, Schaffer's claim that the bringing to salience of a relevant alternative is what undermines knowledge attributions is similarly discredited, as differences in this variable did not affect whether our subjects attributed knowledge. Nevertheless, seemingly in accordance with Stanley's interestrelative view, our subjects were less confident in attributing knowledge to Hannah in High Stakes than in Low Stakes. To account for these results one must develop a better conception of the connection between a subject's interests and her body of knowledge than those offered by Stanley and Schaffer.

\section{The Scenarios}

To test Stanley's and Schaffer's claims empirically, we constructed four scenarios designed to isolate the influence of distinctively practical interests and relevant alternatives on knowledge attributions. Our scenarios differed from Stanley's slightly by having Hannah claim to possess knowledge in all cases. ${ }^{3}$ This alteration enabled us to answer Schaffer's criticisms by removing any mention of Stanley's preferred verdicts while at the same time removing possibly confounding differences in the protagonist's level of conviction. The following are our four vignettes (although, unlike the ones given to our subjects, italics and titles are added here to indicate the differences among them):

\section{Low Stakes-No Alternative (LS-NA)}

Hannah and her wife Sarah are driving home on a Friday afternoon. They plan to stop at the bank on the way home to deposit their paychecks. It is not important that they do so, as they have no impending bills. As they drive past the bank, they notice that the lines inside are very long, as they often are on Friday afternoons. Hannah notes that she was at the bank 2 weeks before on a Saturday morning, and it was open. Realizing that it isn't very important that their paychecks are deposited right away, Hannah says, "I know the bank will be open tomorrow. So we can deposit our paychecks tomorrow morning”.

\section{High Stakes-No Alternative (HS-NA)}

Hannah and her wife Sarah are driving home on a Friday afternoon. They plan to stop at the bank on the way home to deposit their paychecks. Since they have an impending bill coming due, and very little in their account, it is very important that they deposit their paychecks by Saturday. As they drive past the bank, they notice that the lines inside are very long, as they often are on Friday afternoons. Hannah notes that she was at the bank 2 weeks before on a Saturday morning, and it was open. Hannah says, "I know the bank will be open tomorrow. So we can deposit our paychecks tomorrow morning".

\footnotetext{
${ }^{3}$ One might worry that our cases are now biased toward the claim that Hannah does know in both cases. We doubt this is the case. There is a strong concern that Stanley's cases are biased because Hannah provides different verdicts about whether she knows, which may draw attention to a change in response, and that change in response accords with Stanley's preferred verdicts. The force of the concern about Stanley's cases does not derive solely from the fact that Hannah's judgments accord with Stanley's.
} 


\section{Low Stakes-Alternative (LS-A)}

Hannah and her wife Sarah are driving home on a Friday afternoon. They plan to stop at the bank on the way home to deposit their paychecks. It is not important that they do so, as they have no impending bills. As they drive past the bank, they notice that the lines inside are very long, as they often are on Friday afternoons. Hannah notes that she was at the bank 2 weeks before on a Saturday morning, and it was open. Sarah points out that banks do change their hours. Still, realizing that it isn't very important that their paychecks are deposited right away, Hannah says, "I know the bank will be open tomorrow. So we can deposit our paychecks tomorrow morning".

\section{High Stakes-Alternative (HS-A)}

Hannah and her wife Sarah are driving home on a Friday afternoon. They plan to stop at the bank on the way home to deposit their paychecks. Since they have an impending bill coming due, and very little in their account, it is very important that they deposit their paychecks by Saturday. As they drive past the bank, they notice that the lines inside are very long, as they often are on Friday afternoons. Hannah notes that she was at the bank 2 weeks before on a Saturday morning, and it was open. Sarah points out that banks do change their hours. Hannah says, "I know the bank will be open tomorrow. So we can deposit our paychecks tomorrow morning".

Assuming that knowing a proposition requires that it is true, it may seem highly problematic that the truth of the proposition in question - that the bank will be open tomorrow (Saturday) - is not explicitly stipulated in the cases themselves. Despite this worry, we wanted to keep our cases as close as possible to the form in which Stanley presents them, since these are the cases about which he and Schaffer make their claims. Besides, in our experiments reported below, this issue turns out not to be problematic. Most people seem to assume in these cases that the bank will be open on Saturday, since most subjects in our studies attributed to Hannah knowledge of the bank's being open on Saturday.

\section{Between-Subjects Experiment: Stakes and Alternatives}

\subsection{Subjects, Design, and Method}

In our first experiment, we randomly distributed all four of our scenarios to university students (primarily 18-24 years old) in a class or around campus at the University of California, Santa Barbara. Each subject received a sheet of paper with one of the scenarios. Subjects were not told whether their scenario was different from that of the other subjects.

Participants were asked to read the scenario and then respond to this request written on the sheet of paper:

Please check one box to indicate how strongly you agree or disagree with this statement: "Hannah knows that the bank will be open on Saturday". 
Responses were given on a 7-point Likert scale: strongly agree (7), moderately agree (6), slightly agree (5), neither agree nor disagree (4), slightly disagree (3), moderately disagree (2), strongly disagree (1). The numbers were assigned to each response in order to quantify the results.

We collected 241 responses_-about 60 responses per scenario.

\subsection{Results}

Any response above 4.0 indicates agreement (to at least some extent, even if very weak) with the claim that Hannah knows that the bank will be open on Saturday. The mean responses for our scenarios were all significantly above $4.0(p<.05)$, as depicted in Table 1 . Only 17 of $60(28 \%)$ of our subjects denied that Hannah has knowledge in the crucial high stakes case with an alternative (HS-A) by providing a response below 4. Hence, our results disconfirm Stanley's hypothesis that people with an adequate grasp of the concept of knowledge will attribute knowledge to Hannah in LS-NA but not in HS-A. Likewise, these results disconfirm Schaffer's claim that we would deny knowledge in Stanley's HS-A case.

We ran further analyses to determine whether the Stakes variable (low or high) or the Alternative variable (possibility of error mentioned or not) significantly affected our subjects' responses. An analysis of variance conducted on our subjects' degrees of agreement with "Hannah knows that the bank will be open on Saturday" revealed a significant main effect of the Stakes variable $F(1,237)=4.36$, $p=.04$, such that participants were less likely to agree that Hannah knew that the bank would be open when the stakes were high. However, contra Schaffer, the mention of the alternative ("banks do change their hours") did not have a significant effect on whether subjects attributed knowledge $(\mathrm{F}(1,237)=1.16, p>.25)$, nor did the two variables interact $(\mathrm{F}(1,237)=.87, p>.25)$. So, while the mean responses reported in Table 1 may seem to indicate that the two variables are working together in HS-A to lower degrees of agreement among subjects, only Stakes had a main effect.

These data seem to indicate two things. First, participants' responses did not produce the pattern predicted by either Stanley or Schaffer. Second, however, practical interests did, whereas alternative possibilities did not, affect the level of confidence our subjects had in their attributions of knowledge. (We will assume that degree of agreement with a claim reflects a person's level of confidence in the truth of that claim. But even if this is incorrect, our main theses will not be adversely affected.)

\section{Within-Subjects Experiment: Stakes and Order}

Factors that make a difference but do not drive answers across the midline in between-subjects studies sometimes do push answers across the midline in within-

Table 1 Mean responses for between-subjects experiment

\begin{tabular}{lll}
\hline & NA & A \\
\hline LS & 5.33 & 5.30 \\
HS & 5.07 & 4.60 \\
\hline
\end{tabular}


subjects studies. Hence, we wondered whether subjects would sense a difference and say that Hannah knows in LS-NA but not in HS-A, as Stanley predicted, if each subject were asked about both of Stanley's original scenarios (LS-NA and HS-A) at once. When subjects see the two cases side-by-side, they might provide different answers in response to a sensed difference between the cases. After all, a similar result was recently found in a study conducted by Ram Neta and Mark Phelan (ms), though it was on folk intuitions regarding anti-intellectualism about evidence, not knowledge.

Moreover, when subjects receive multiple scenarios, the order of presentation sometimes affects responses. Stanley denied that his intuitions result from such framing effects (pp. 9-11), but no data were offered to support this.

To test these hypotheses, we performed a second experiment.

\subsection{Subjects, Design, and Method}

In this second experiment, the subjects were of the same type as in the first experiment (university students primarily 18-24 years old). We also used the same 7-point Likert scale for tracking subjects' responses.

Our second design differed from our first in the following respects. We used only the two scenarios that most closely match Stanley's (LS-NA and HS-A), and both scenarios were presented to each subject. We tracked ordering effects by presenting half of the subjects with LS-NA first (followed by HS-A) and presenting the other half of the subjects with HS-A first (followed by LS-NA). We collected responses from 298 university students, about half in each ordering.

\subsection{Results}

The mean responses for our two scenarios in the two orders are depicted in Table 2. As in the between-subject experiment, these means are all above 4.0, and any response above 4.0 indicates agreement (to at least some extent, even if very weak) with the claim that Hannah knows that the bank will be open. Only 93 of 298 (31\%) of our subjects denied that Hannah had knowledge in HS-A (i.e. provided a response below 4). Even fewer (47 of 298 or 16\%) provided Stanley's preferred verdicts by agreeing in LS-NA and disagreeing in HS-A. Hence, these results provide additional evidence against Stanley's hypothesis that competent speakers will attribute knowledge to Hannah in LS-NA but not in HS-A.

Nonetheless, the amount at stake for Hannah once again had a significant main effect, $\mathrm{F}(1,296)=57.20, p<.001$, as subjects were likely to agree less strongly with the statement, "Hannah knows that the bank will be open on Saturday", under high than under low stakes conditions. However, contra Stanley, order did have an effect,

Table 2 Mean responses for within-subjects experiment

\begin{tabular}{lcc}
\hline & LS-NA & HS-A \\
\hline LS-HS order & 5.61 & 4.59 \\
HS-LS order & 4.60 & 4.21 \\
Both orders & 5.13 & 4.42 \\
\hline
\end{tabular}


$\mathrm{F}(1,296)=13.51, p<.001$, reflecting anchoring: agreement was greater when the low rather than the high stakes context was described first. Finally, we observed a significant interaction of Stakes and Order, $\mathrm{F}(1,296)=11.50, p<.001$, such that the difference between the high and low stakes context was greatest when the low stakes context was presented first. This is a fairly significant finding given that Stanley presents his cases in this ordering.

\section{Discussion}

What are we to make of these results? It now seems clear that, contra both Stanley and Schaffer, we don't tend to judge in Stanley's versions of the bank cases that Hannah knows in LS-NA but not in HS-A. But what about the status of the epistemologies that each philosopher is attempting to underwrite by appeal to common-sense judgments about these cases? While further research is needed before rendering a verdict on that matter, there are several conclusions we think we can reasonably draw from our results regarding this issue.

First, it seems that describing alternative possibilities in a minimal way (such as "Banks do change their hours") does not affect our willingness to attribute knowledge in cases such as ours. Even though Hannah's knowledge that the bank will be open on Saturday rests on the assumption that the bank has not eliminated its Saturday hours, mentioning this possibility does not even affect our confidence that Hannah knows that the bank will be open. Thus, some doubt is cast on the soundness of arguments for a contextualist or relevant alternatives account of knowledge that appeal to its capturing common-sense or ordinary linguistic practice with respect to these bank cases.

Of course, Schaffer and other similar theorists might argue that the alternative possibilities described must be more likely than a bank's suddenly changing its hours, or that alternatives of this kind must be presented in more detail to fully achieve salience of the alternative and thus erode the attribution of knowledge. However, even if for any reason we failed to make the alternative appropriately salient in our LS-A and HS-A cases, a salience-only approach is still ill-equipped to explain our data. It simply doesn't explain the observation in our first experiment that Stakes has an effect on confidence across conditions involving no alternative at all (i.e. LS-NA and HS-NA). ${ }^{4}$

Second, it seems that a person's practical interests affect our confidence in attributing knowledge, but this difference does not determine whether we do credit her with knowledge, at least in these bank cases. Thus, some doubt is cast on the cogency of attempts to support such a version of anti-intellectualism by appealing to its capturing common-sense or ordinary linguistic practice with respect to these bank cases. But, of course, our results don't address other arguments for Stanley's view, such as appeals to principles connecting knowledge and action.

In defense of their view being in accord with common sense, Stanley and other interest-relativity theorists could of course speculate that when the stakes are made more severe, this fact will prod us into denying knowledge. (Perhaps if Hannah's and

\footnotetext{
${ }^{4}$ For further research on contextualism and the bank cases, see Wesley Buckwalter (forthcoming).
} 
Sarah's lives depended on the bank's being open in HS-NA, we would deny Hannah knowledge of the bank's Saturday hours.) Though the interest-motivated differences in level of confidence that we observed in our study lend some plausibility to this hypothesis, the matter requires further empirical investigation. ${ }^{5}$

After all, anti-intellectualism is not the only way to explain the effect of practical interests on our confidence in our knowledge attributions. There might be a plausible explanation of why high stakes affects confidence that is available to the traditional intellectualist about knowledge. Perhaps, for example, subjects attribute knowledge in both high stakes and low stakes cases because of Hannah's fairly robust evidence (having been to the bank 2 weeks prior on a Saturday), but subjects refrain from agreeing with full confidence that Hannah knows in high stakes cases because they think of this unmitigated response as suggesting that they think it is a good idea for Hannah and Sarah to perform a certain action-namely, wait until Saturday to deposit their paycheck. Since the chances of disaster are there in the high stakes case (even if ruled out by the knowledge they are willing to attribute to Hannah, however hesitantly) but not there at all in the low stakes case, subjects are reluctant only in high stakes cases to appear relatively confident in their knowledge attribution.

Stanley, Schaffer, and other epistemologists in their respective camps might respond to the data by denying that their theories are about common-sense knowledge attributions. But then they cannot easily say, as Stanley does: "My philosophical tendency is to preserve as much as possible of common-sense intuition" (p. v). Indeed, if we intend our theories to capture the shared conceptual framework that underlies our common-sense intuitions about cases, we need to determine more precisely what common-sense intuition is and how it changes with circumstances.

Acknowledgment We would like to thank Matthew McGrath, Jonathan Schaffer, Jennifer Nagel, Geoff Pynn, and two anonymous referees for their helpful comments on earlier drafts of this paper. Thanks also to Garrett Glasgow, Bruce Bimber, Ian Nance, and Jonathan Way for help along the way.

Open Access This article is distributed under the terms of the Creative Commons Attribution Noncommercial License which permits any noncommercial use, distribution, and reproduction in any medium, provided the original author(s) and source are credited.

\section{References}

Buckwalter, W. forthcoming. Knowledge isn't closed on Saturday. Review of Philosophy and Psychology. Fantl, J., and M. McGrath. 2002. Evidence, pragmatics, and justification. Philosophical Review 111: 67-94. Feltz, A., and C. Zarpentine. in press. Do you know more when it matters less? Philosophical Psychology. Hawthorne, J. 2004. Knowledge and lotteries. Oxford: Clarendon Press.

Neta, R., and M. Phelan. manuscript. Evidence that stakes don't matter to evidence.

Schaffer, J. 2006. The irrelevance of the subject: against subject-sensitive invariantism. Philosophical Studies 127: 87-107.

Stanley, J. 2005. Knowledge and practical interests. Oxford: Clarendon Press.

\footnotetext{
${ }^{5}$ However, such results were not found in a recent study conducted by Adam Feltz and Chris Zarpentine (in press). They ran several experiments involving the bank cases and several other vignettes, including some in which the stakes were higher. Yet their data did not produce the patterns that the antiintellectualist would predict.
} 